\title{
Management of Impacted Urethral Calculi: An Uncommon Cause of Acute Urine Retention in North-western Nigeria
}

\author{
Ngwobia Peter Agwu*, Abdullahi Abdulwahab-Ahmed, Abubakar Muhammadu Sadiq, \\ Emmanuel Ugbede Oyibo, Ismaila Arzika Mungadi
}

Urology Unit, Department of Surgery, Usmanu Danfodiyo University Teaching Hospital, Sokoto, Nigeria

\section{Email address:}

npagwu@gmail.com (N. P. Agwu),npagwu@yahoo.com (N. P. Agwu), abdulneuro@yahoo.com (A. Abdulwahab-Ahmed), asmgusau@gmail.com (A. M. Sadiq), ugbedeoyibo@gmail.com (E. U. Oyibo), imungadi@yahoo.com (I. A. Mungadi)

${ }^{*}$ Corresponding author

\section{To cite this article:}

Ngwobia Peter Agwu, Abdullahi Abdulwahab-Ahmed, Abubakar Muhammadu Sadiq, Emmanuel Ugbede Oyibo, Ismaila Arzika Mungadi. Management of Impacted Urethral Calculi: An Uncommon Cause of Acute Urine Retention in North-western Nigeria. International Journal of Clinical Urology. Vol. 4, No. 1, 2020, pp. 1-5. doi: 10.11648/j.jicu.20200401.11

Received: November 4, 2019; Accepted: December 12, 2019; Published: January 7, 2020

\begin{abstract}
Urethral stones though rare manifestation of urolithiasis may be primary but mostly are secondary arising from either the urinary bladder or the upper tract. When impacted in the urethra may result in acute urinary retention and difficulty in urethral catheterization. Various treatment modalities are available ranging from initial suprapubic cystostomy and subsequent open surgical or endoscopic procedures as well as treatment of associated urethral pathology. We report our experience in the management of patients with acute urine retention due to impacted urethral calculi in a tertiary hospital. This was a retrospective review of forty patients with impacted urethral stones managed at the Urology Unit, Department of Surgery Usmanu Danfodiyo University Teaching Hospital Sokoto from January 2005 to December 2015. Data were collected from patients' case notes and entered in to a proforma and analysed using SPSS 20.0 version for Windows. Forty patients comprising of one female (2.5\%) and 39 males (97.5\%), mean age was $25 \pm 17.4$ years with a range of 1-63yrs. In twenty patients $(50 \%)$, attempt at urethral catheterization was not successful. Location of the impacted calculi were meatal $7(17.5 \%)$, distal penile $4(10 \%)$, mid penile $8(20 \%)$, proximal penile $1(2.5 \%)$, bulbar $4(10 \%)$, peno-bulbar junction 3 (7.5\%), posterior urethra $11(27.5 \%)$, and bladder neck $2(5 \%)$. Spontaneous extrusion of the calculi occurred in $4(10 \%)$, while expulsion occurred in $2(5 \%)$ after intra-urethral instillation of $2 \%$ lidocaine jelly. Other treatment modalities in the remaining patients included; meatotomy $11(27.5 \%)$, open urethrolithotomy $6(15 \%)$, urethroscopy and pneumatic lithotripsy $6(15 \%)$, urethroscopy and stone retrieval 1 (2.5\%), urethrolithotomy and urethroplasty $2(5 \%)$, and cystolithotomy $8(20 \%)$. Impacted urethral stone may be a cause of acute urinary retention and failed urethral catheterisation. The stone can pass spontaneously with or without manipulation or can be removed by endoscopic or open technique when spontaneous passage is not successful.
\end{abstract}

Keywords: Impacted Urethral Calculus, Acute Urine Retention, Failed Urethral Catheterization and Management

\section{Introduction}

Urinary calculus disease has been a common affliction of mankind from antiquity though currently, there is increasing incidence and prevalence world-wide [1]. The history of this entity has shared similar course with human civilization as changes in socio-economic conditions have also affected changes in dietary habits and these influence the locations and chemical compositions of urinary calculi [2-4].
Clinical presentation of urinary tract calculi depends on the size, location and other associated patho-anatomic conditions of the patient. Urethral calculi are not common and may account for less than $1 \%$ of urinary stone disease [5]. The stone in the urethra may be primary; being formed in the presence of existing urethral pathology such as stricture or diverticulum. Secondary urethral calculi occur as a result of antegrade migration from either the kidneys, ureters or urinary bladder [6]. Clinical presentation of primary urethral stones may vary 
depending on the location and this ranges from asymptomatic cases to symptoms of ano-genital pain, frequency, weak urine stream, haematuria, urethral discharge and acute urine retention and rarely renal failure $[7,8]$. Secondary calculi arise from the upper urinary tract and may present after initial episodes of renal colic and flank tenderness. Stones arising from the bladder may cause severe supra-pubic pain or acute urine retention [9]. Other rarer manifestations of urethral calculus disease include penile gangrene, iliac vein compression syndrome, and scrotal mass with urethra-cutaneous fistula [10-13].

This study highlights our experience in the management of patients who presented to our practice with imparted urethral stones.

\section{Methods}

This was a retrospective review of medical records of patients who presented with acute urine retention due to urethral stones at the Urology Unit of the Usmanu Danfodiyo University Teaching Hospital, Sokoto, north-western Nigeria from January 2005 to December 2015. Relevant demographic data including age, sex, presenting symptoms, location of the stones, associated disposing pathologic factors and modes of treatment were entered into a proforma. The data was analyzed using the SSPS statistical software and the results expressed as means and percentages.

\section{Results}

There were forty patients with impacted urethral stones within the period of study with mean age of $25.0 \pm 17.4$ years and age range of 1-63 years. There were 39 males $(97.5 \%)$ and 1 female patient $(2.5 \%)$. Eighteen patients $(45.0 \%)$ had lower urinary tract symptoms (LUTS) culminating in acute urine retention. Twenty-two patients $(55 \%)$ were referred due to failed urethral catheterization. The locations of the urethral stones are shown in Table 1 below.

Table 1. Locations of the urethral stones

\begin{tabular}{lll}
\hline Location & Number of patients & Percentage (\%) \\
\hline Meatal & 7 & 17.5 \\
Distal penile & 4 & 10.0 \\
Mid-penile & 8 & 20.0 \\
Proximal penile & 1 & 2.5 \\
Bulbar & 4 & 10.0 \\
Peno-bulbar & 3 & 7.5 \\
Posterior urethra & 11 & 27.5 \\
Bladder neck & 2 & 5.0 \\
Total & 40 & 100.0 \\
\hline
\end{tabular}

Associated urethral abnormalities were present in 18 $(45 \%)$ and consisted of meatal stenosis $8(20 \%)$, urethral stricture $7(17.5 \%)$, posterior urethral valves, phimosis and benign prostatic hyperplasia with stricture were each in 1 patient $(2.5 \%)$. Treatment offered to patients is shown in Table 2, Figures 1, 2, 3.
Table 2. Treatment offered.

\begin{tabular}{lll}
\hline Type of treatment & $\begin{array}{l}\text { Number of } \\
\text { patients }\end{array}$ & $\begin{array}{l}\text { Percentage } \\
\text { (\%) }\end{array}$ \\
\hline Spontaneous passage & 4 & 10.0 \\
Passage after urethral instillation of & 2 & 5.0 \\
Xylocaine jelly & 11 & 27.5 \\
Meatotomy & 6 & 15.0 \\
Urethrolithotomy & 8 & 20.0 \\
Cystolithotomy & 6 & 15.0 \\
Urethroscopy + pneumatic lithotripsy & 2 & 5.0 \\
Urethrolithotomy + urethroplasty & 1 & 2.5 \\
Urehroscopy + stone retrieval & 40 & 100.0 \\
Total & & \\
\hline
\end{tabular}

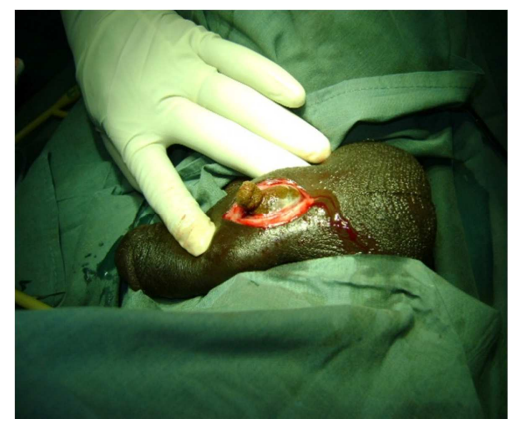

Figure 1. Ventral urethrotomy.

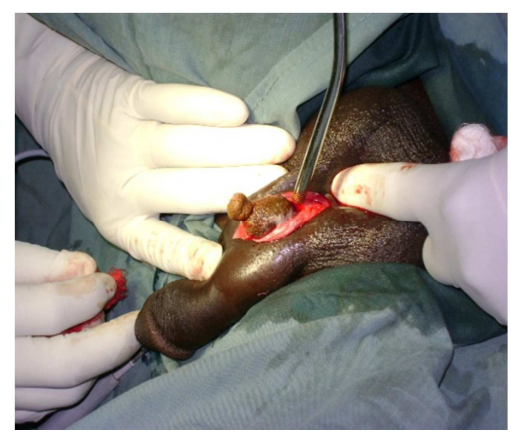

Figure 2. Extraction of the impacted calculus.

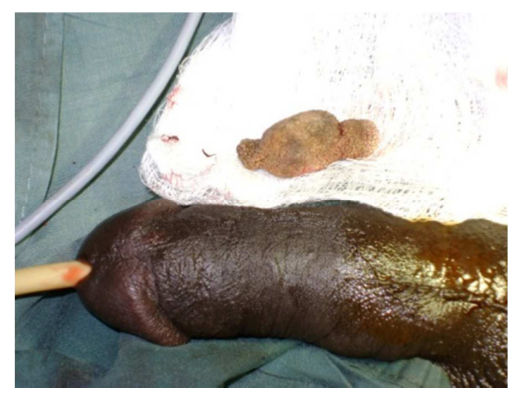

Figure 3. The extracted calculus and wound closure.

\section{Discussion}

Urethral calculi are rare manifestation of urolithiasis. Publications on urethral calculus disease are few and most articles are case reports involving very few of patients $[9,14-$ 15]. The present study involves forty, patients who presented to our practice during the period of study. This is the largest number of cases we could find in the literature. This may as a result of the fact that this study was carried out in a referral 
tertiary hospital that caters for a large population of people residing in a stone endemic region commonly called the stone belt as reported by Mungadi et al [16]. All the patients were males except one confirming the rarity of urethral calculi in female [17]. The male-female disparity in the incidence of urethral calculi is due to the anatomic differences between the male and female urethra and the pathologic risk factors such as the presence of phimosis, meatal stenosis, strictures, benign and malignant prostatic obstruction and posterior urethral valves in male children $[18,19]$.

The subjects in this study were referred to our unit with lower tract symptoms and acute urine retention and in 55\% of the subjects, there was failed urethral catheterization. Impacted urethral stones have been known to be the cause of acute urine retention in men, women and children especially in stone endemic regions of the world $[8,17,20]$. Acute urine retention (AUR) is the sudden inability to pass urine and is associated with severe physical and emotional stress to the patient [20]. It has been commonly seen in elderly men due to the occurrence of benign prostatic hyperplasia but rare in women [21-23]. Acute urine retention is rare in the female although it has been reported in patients with haematocolpos [24], retroverted gravid uterus [25], and endometrial cancer [26]. The patients in this series developed acute urine retention and attempts at urethral catheterization were unsuccessful in $55 \%$ of them and this necessitated initial urinary diversion via supra-pubic cystostomy. The failure to catheterize these patients could have been caused directly by the obstructing calculi or as a result of the pre-existing urethral pathology such as urethral stricture.

Most of the obstructing calculi were located in the penile urethra than in the bulb due to the narrower diameter of the former such that larger diameter calculi migrating from the kidneys, ureters and the urinary bladder that might have traversed the wider bulbar urethra were impacted in the narrower penile portion.

In this study the anatomic cause of the urethral calculi impaction could not be found in $55 \%$ of the subjects and these cases could be due to calculi migrating from the bladder or upper tract. Kamal et al [27] found that only $6 \%$ of their patients with urethral stones had a known urethral anatomic pathology unlike in the current study where $45 \%$ of the patients had identified anatomic cause of urethral calculi. This disparity reflects the regional differences in the incidence of urethral stricture disease, meatal stenosis, the composition as well as the types of urinary stone disease among the two populations studied [3]. The stones in patients with known urethral pathology may be primary urethral calculi and may have resulted from urinary stasis and infection though no stone analysis was done in this study to actually determine the stone chemical compositions. Meatal stenosis is an important pathology found in this series and this finding of meatal stenosis may be associated with one of the complications of neonatal and childhood circumcision routinely carried out for religious and cultural reasons in our environment [28-30]. In women, urethral calculi have been associated with urethral pathology such as diverticulum [31, 32] however, in the only female in this series, there was no identifiable urethral pathology as has been similarly reported by Turo et al [17].

Management of urethral calculus disease varies according to the clinical presentation, calculi size, location, associated urethral pathology such as; stricture, diverticulum, meatal stenosis, as well as the urologist's training, experience and the availability of appropriate technology [33]. Impacted urethral calculi causing acute urine retention is an emergency as it presents with severe pain and thus every effort must be put to relieve the retention in order to forestall preventable complications as definitive treatment may not be possible in presence of the urine retention [8, 34].

Posterior urethral calculi may be retrogradely pushed back into the bladder for subsequent electrohydaulic or laser fragmentation where these technologies are available. However, in our practice, we have managed some of our patients by urethroscopy and pneumatic lithotripsy or by open cystolithotomy after initial retrograde manipulation into the bladder. El-Sherif [35] et al reported their experience of using extracorporeal shock wave lithotripsy in stone fragmentation after retrograde manipulation into the urinary bladder. However, this technology is not yet available in our practice.

Anterior urethral calculi may be present anywhere from the external meatus to the bulbo-membranous junction. Patients may experience spontaneous passage of the stones during attempt at micturating with a full bladder as was observed in some of the patients in this study.

These patients who had spontaneous passage of stones and those that expelled the stone following intra-urethral instillation of $2 \%$ lidocaine jelly with or without ventral meatotomy were those that had small sized stones, located in the distal penile urethra and had no associated urethral pathology such as stricture. The practice of open surgery for dealing with urethral calculi is still common in our practice as some of the patients underwent stone extraction after meatotomy, urethrolithotomy and cystolithotomy. Management of urethral calculi that is associated with stricture involves removal of the stone and treatment of the stricture at the same time or as part of staged urethroplasty. The determining factors in these patients are the location, size of calculi, degree of spongiofibrosis and the length of the stricture. Urethral reconstruction and removal of the calculi as part of one-stage procedure has been reported by Kotka et al [15]. Large urethral calculi obstructing outflow in the absence of stricture may be managed by open urethrolithotomy even in more advanced urologic practice as similarly reported by Kaczmarek et al [36]. However, larger bulbar urethral calculi in the presence of short-segment stricture with near complete urethral lumen obliteration may be managed by urethrolithotomy and end-to-end anastomotic urethroplasty and this has been reported by Banapour et al [37]. Some bulbar urethral calculi in some of our patients were managed by endoscopic treatment that included urethroscopy and stone retrieval, urethroscopy, direct visual 
internal urethrotomy and pneumatic lithotripsy similar to the report of Sureka el al [38].

\section{Conclusion}

Impacted urethral stone may be a cause of acute urinary retention and failed urethral catheterisation in a stone endemic region. Relief of the acute urine retention should be prompt followed by procedures to remove the obstructing calculi as well as treating any associated urethral pathology. Open surgical procedures for treatment of impacted urethral calculi is still common in our practice. Practitioners in stone endemic regions should suspect impacted urethral stone as a possible cause of acute urine and failed catheterization in male patients.

\section{References}

[1] Knoll, Thomas. Epidemiology, Pathogenesis and Pathophysiology of Urolithiasis. European Urology Supplement 2010: 9: 802-806.

[2] Tefekli Ahmet, Cezayirli Fatin. The History of Urinary Stones: In Parallel with Civilization. The Scientific World journal, Volume 2013, Article ID 423964, 5 pages. http//dx.doi.org/10.11551/2013/423964.3.

[3] Lopez, Michelle, Hoppe, Bernd. History, epidemiology and regional diversities of urolithiasis. Pediatr Nephrol, 2010; 25: 49-59.

[4] Trinchieri Alberto. Epidemiology of urolithiasis: an update. Clinical Cases in Mineral and Bone Metabolism 2008; 5 (2): 101-106.

[5] Krishna Prasad K, Keerthi N, Praveen GP, Amal Abraham. A rare case of Giant Penile Urethral Calculus. International Journal of Sciences and Research (IJSR) 2016; 5 (9): 532-533.

[6] Agarawal A, Sigdel G, Beloker WK. A rare case of giant urethral calculus and multiple urethral diverticulum. Journal of Medical Sciences- Nepal, 2012; 8 (2): 46-48.

[7] Benway BM, Bhayani SB. Lower Urinary Tract Calculi. In Campbell-Walsh Urology. Ed. Kavoussi LR, Novick AC, Partin AW, Peters CA. 10th Edition, Elsevier Saunders, Philadelphia PA 19103-2899, pages 2529-2532.

[8] Beilawske H, Epstein Norman L. A stone down below: a urethral stone causing acute urinary retention and renal failure. CJEM 2010, 2 (4) 377-380.

[9] Mark FG, Mador ML. Urethral Calculi. Canad MAJ. 1950; 54: 186-188.

[10] Ramdass MJ, Singh VN. Multiple Urethral stones causing Penile gangrene. Case Rep Urol 2014; 1-3.

[11] Akiko Ikegami et al. Iliac vein Compression Syndrome due to Bladder Distension caused by Urethral Calculi. Hindawi Publishing Corporation Case Reports in Urology Volume 22015 Article ID. $743270 \quad 3$ pages. http//dx.doi.org/10.1155/2015/743270.

[12] Prakash J, Sharma P, Sankhwar S, Goel A. Large anterior urethral calculus presented as scrotal mass with urethrocutaneous fistula. BMJ Case Reports 2013. doi

\subsection{6/bcr-2013-200805.}

[13] Bello A., Maitama HY, Mbibu HN, Kalayi GD and Ahmed A. Unusual Giant Prostatic Urethral Calculus. J. Surgery Tech. Case Report 2010; 2 (1): 30-32 doi: 104103/2006-8808.63721.

[14] Win T. Giant urethral calculus Singapore Med J. 1994; 35: 44415.

[15] Kotkar K, Thakkar R, Songra MC. Giant Urethral Calculus. JS CR 2011; 8: 9.

[16] Abubakar AM, Mungadi IA, Chinda JY, Ntia IO, Jalo I and Obianno SK. Paediatric urolithiasis in northern Nigeria. African Journal of Paediatric Surgery 2004; 1: 2-5.

[17] Turo F, Smolski M, Kujawa M, Brown SCW, Brough R and Collins NC. Acute urine retention in women due to urethral calculi. A rare case. Can Urol Assoc J 2014; 8 (1-2): 99-10. http//dx.doi.org/105489/cuaj.1573.

[18] Okeke LI, Takure AD, Adebayo SA, Oluyemi OY, Oyelekan AAA. Urethral Obstruction from dislodged bladder Diverticular Stones: a case report. BMC Urology 2012; 12: 3 http://www.biomedicentral.com/1471-2490/12/31.

[19] Speekman MJ, Cheng Xi. Management of Complications of BPH/BOO. Indian J Urol. 2014; 30 (2): 208-213.

[20] Embertom M, Ansner K. Acute urinary retention en men: an age-old problem. BMJ 1999; 3: 92210925.

[21] Roehborn CG. Acute urinary retention risks and management Rev. Urology 2005; (supp/4); 531-542.

[22] Ugare UG, Bassey IA, Udosen EJ, Essiet A. Bassey OO. Management of lower urinary retention in limited resource setting. Ethio J Health Science 2014; 24 (4): 329-336.

[23] Mevche A, Drake MJ. Etiology and management of urinary retention in women. Indian J Urol. 2010; 26 (2): 230-235.

[24] Christodoulidon M, Keba R, Octes J, Wemyss-Holden GD. Acute urinary retention in an adolescent girl and important learing point. BMJ case report 2013. Doi: 10.1136/bcr-2013010361 .

[25] Suzuki S, Ono S and Satomi M. recurrence of urinary retention secondary to retroverted gravid uterus. N AM J Med Sci. 2009. July 1 (2): 54-59.

[26] Tannus SR, Atlas I. Endometrial cancer presenting as AUR: a case report and review of literature cases journal 2009, 2: 9382.

[27] Kamal BA, Anikwe RM, Parahani H, Hashish M Taha SA. (2004). Urethral calculus: presentation and management BJU International 93 (4), 549-502.

[28] Krill AJ, Palmer LS, Palmer JS complications of circumcision Scientific World Journal 2011; 11: 2458-2468.

[29] Nnamonu MT. Circumcision experience at a private Hospital in Jos, Nigeia. Niger J. Surg. 2013; 19: 1-3.

[30] Lawal TA, Olapade-Olaopa EO. Circumcision and its effects in Africa. Transl Androl Urol 2017; 6 (2): 149-157.

[31] Dong ZhiLong, Wang Hanzhang, Zuo LinJung, Hou Minghi. Female Urethral Diverticulum Containing a Giant Calculus. A CARE-Compliant Case Report. Medicine 2015; 94 (20): e826. 
[32] Shim JS, Oh MM, Kang J II. Calculi in female urethral diverticulum. Int Neuro-urol J, 2011; 15: 55-58.

[33] Prabhuswanny V K, Tiwari R and Krishnamoorthy R. A Giant Dumbell Shaped Vesico-Prostatic Calculus: A case Report and Review of Literature. Case Reports in Urology, Volume 2013, Article ID 167635, 5 pages, http://doi/ 10.1155/2013/167635.

[34] Akhtar J, Ahmad S, Zamir N. Management of Impacted Urethral Stones in children. Journal of the College of Physicians and Surgeons of Pakistian 2012, 22 (8): 510-513.

[35] El-Sarif, Prasad K. treatment of urethral stones by retrograde manipulation and extracorporeal shock wave lithotripsy. Br J urol. 1995; 76 (6): 761-764.
[36] Kaczmarek K, Goteb A, Soczawa M, Stojewski M. urethral stone of unexpected size: case report and short literarure review. Open Med. 2016; 11: 7-10.

[37] Banapour P, Tenggardaja C, Reyblat P. Anastomotic Urethroplasty for an Obstructing Calculus within a Bulbar Urethral Diverticulum and Stricture. Urology Case Reports 2017; 10: 54-56.

[38] Vashishtha S, Sureka SK, Agarwal S, Srivastava A, Prabhakaran $S$ et al. Urethral stricture and stone: their coexistence and management. Urology Journal 2014; 11: (1): 1204-1210. 